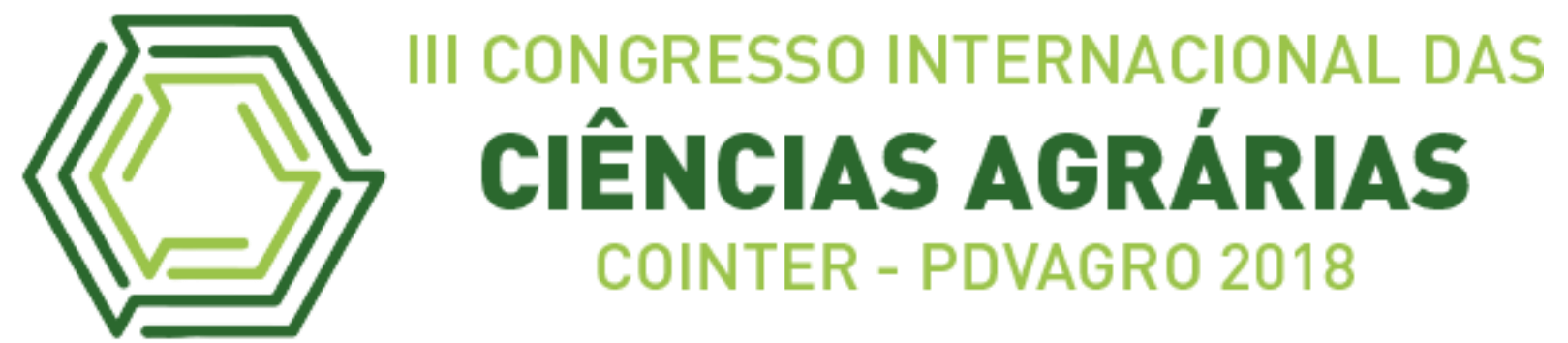

\title{
ESTOQUE DE NITROGÊNIO EM SOLO SOB SISTEMA AGROFLORESTAL COM SERINGUEIRA E AÇAÍ
}

\section{NITROGEN STOCK IN SOIL UNDER AGROFLORESTAL SYSTEM WITH RUBBER TREE AND AÇAI}

Apresentação: Pôster

Ana Paula Brito de Sousa ${ }^{1}$; Rayara Barros Silva ${ }^{2}$; Jacqueline de Oliveira ${ }^{3}$; Mickaelle Alves de Sousa Lima ${ }^{4}$; Gerbeli de Mattos Salgado ${ }^{5}$

\section{DOI: https://doi.org/10.31692/2526-7701.IIICOINTERPDVAGRO.2018.00473}

\section{Introdução}

O nitrogênio $(\mathrm{N})$ é um dos nutrientes mais abundantes nos solos, porém apenas uma pequena fração desse elemento fica disponível na forma mineral, enquanto o restante permanece complexado em formas orgânicas, indisponível às plantas (CAMARGO et al. 2008). É essencial para estrutura e funções nas células; para todas as reações enzimáticas nos vegetais, faz parte da molécula de clorofila (fotossíntese), um dos macronutrientes primário sendo o mais utilizado, mais absorvido e mais exportado pelas culturas; nutriente de obtenção mais cara; é o mais lixiviado nos solos, requerendo cuidados especiais em seu manejo pelos riscos de contaminação do lençol freático (CARVALHO; ZABOT, 2012).

Sistemas agroflorestais (SAF's), caracterizados pelo cultivo integrado de espécies agrícolas e silviculturais na mesma área, obtêm valorosa funcionalidade, por possuírem a capacidade de exercer restauração ecológica tanto por meio de espécies exóticas quanto por meio de vegetação nativa. (ENGEL; A PARROTA, 2008). Segundo Veiga et al. (2000), os sistemas agroflorestais tem-se mostrado eficientes na ciclagem de nutrientes e no aporte de matéria orgânica, o que contribui para maior disponibilidade de nitrogênio no solo. O objetivo

\footnotetext{
${ }^{1}$ Engenharia Florestal, Universidade Estadual da Região Tocantina do Maranhão, paulabrito.1619@gmail.com

${ }^{2}$ Engenharia Florestal, Universidade Estadual da Região Tocantina do Maranhão, barrosrayara@gmail.com

${ }^{3}$ Engenharia Florestal, Universidade Estadual da Região Tocantina do Maranhão, jacqueolvs@gmail.com

4 Engenharia Agronômica, Universidade Estadual da Região Tocantina do Maranhão, mickaellesousalima@gmail.com

5 Doutora em Produção Vegetal, Universidade Estadual da Região Tocantina do Maranhão, gerbeli_salgado@hotmail.com.
} 
do presente estudo foi avaliar a capacidade de sistemas agroflorestais com seringueira + açaí de estocar o Nitrogênio no solo a $100 \mathrm{~cm}$ de profundidade.

\section{Fundamentação Teórica}

O N é um elemento relevante nos estudos de matéria orgânica do solo, sendo um dos nutrientes com dinâmica mais pronunciada no sistema.

A seringueira (Hevea brasiliensis Muell. Arg.) possui uma grande aptidão para uso em sistemas agroflorestais, pois antes mesmo da primeira sangria realizada nas plantas para extração do látex, pode-se inserir cultivos nas entrelinhas da cultura, uma vez que seu espaçamento proporciona espaço suficiente para adoção de consórcio com outras culturas (ABDO et al., 2012); possui uma grande capacidade de produção de biomassa. Saengruksawong et al. (2012), em estudos com seringueira na Tailândia, relatam que a espécie pode chegar a produzir $3,2 \mathrm{~kg}$ de biomassa aérea por árvore com 1 ano de idade, podendo chegar a 264,9 kg por árvore aos 20 anos. É um exemplo de espécie arbórea que vem sendo usada em SAF's, consorciada com diversas culturas, dentre elas o açaí.

A palmeira Euterpe oleracea Mart., conhecida como açaizeiro, é uma palmeira tropical nativa da Amazônia Brasileira, e pode ser considerada como a palmeira de maior importância econômica, social e cultural da região Norte do Brasil (QUEIROZ e MELEM JÚNIOR, 2001). A agroindústria do açaí produz grande quantidade de resíduos sólidos, tanto na exploração dos frutos quanto na do palmito. A disponibilidade desses resíduos para a matéria orgânica é elevada e enriquece o solo de forma gradativa (TEIXEIRA, et al. 2005).

Esses sistemas proporcionam maior cobertura do solo, promovem a ciclagem de nutrientes a partir da ação de sistemas radiculares diversos e propiciam contínuo aporte de resíduos orgânicos (SCHROTH, et al. 2002).

\section{Metodologia}

As áreas de estudo estão localizadas no município de Una, Sul do Estado da Bahia, Brasil, distribuídas em um LATOSSOLO VERMELHO de baixa fertilidade natural. O clima da região é tropical úmido ou superúmido (AF Köppen), com pluviometria média de 2000 mm e temperatura média de $25^{\circ} \mathrm{C}$.

Os sistemas utilizados foram: Floresta secundária, usada como referência para os demais sistemas; Pasto, composto por Brachiaria decumbens, com 8 anos de idade; antes do pasto a área passou por período de abandono com predomínio de plantas daninhas; SAF 
Seringueira (Hevea brasiliensis) + açaí (Euterpe oleraceae), SAF com 30 anos de idade, composto por seringueiras e açaí. As seringueiras, encontravam-se com espaçamento de 7x3 m, com um total de 476 plantas ha ${ }^{-1}$ e no centro da entre linha o açaí com 7x3 m, com um total de 476 plantas ha ${ }^{-1}$. O plantio do açaí tinha como objetivo a produção de palmito.

As amostras de solo foram coletadas na parte central de cada sistema, foram delimitadas quatro parcelas de $30 \mathrm{~m}^{2}$ distantes entre si por aproximadamente $100 \mathrm{~m}$, onde foi aberta quatro trincheiras de $1 \times 1 \times 1,5 \mathrm{~m}$, entre as linhas das culturas. Em cada trincheira o solo foi coletado em seis camadas $(0-10,10-20,20-40,40-60,60-80$ e 80-100 cm de profundidade), totalizando 24 amostras por área, bem como coletadas amostras indeformadas com auxílio de anel volumétrico para determinação da densidade que foi usada para o cálculo do estoque.

O nitrogênio foi determinado em seis camadas: 0-10; 10-20; 20-40; 40-60; 60-80 e 80$100 \mathrm{~cm}$ de profundidade. Para determinação do $\mathrm{N}$ as amostras de solo coletadas, foram secas ao ar e passadas em peneira de $2 \mathrm{~mm}$. Em laboratório, uma subamostra foi macerada em almofariz, passada em peneira de $150 \mu \mathrm{m}$ e seca em estufa de circulação de ar a $60^{\circ} \mathrm{C}$ por 96 h. Em seguida foi analisado o teor de $\mathrm{N}$ por combustão seca usando um sistema analisador elementar automatizado Perkin-Elmer Series II 2400 HNS/O Analyze. Para o cálculo de estoque de nitrogênio foi utilizada a seguinte fórmula: $\mathrm{EN}=\% \mathrm{~N} \mathrm{x} \mathrm{d}\left(\mathrm{g} \mathrm{cm}^{3}\right) \times 10$.

Em cada sistema de uso da terra as trincheiras foram tratadas como pseudorrepetições como em outros estudos com sistemas florestais e agroflorestais (VICENTE, et al. 2016) Como todas as trincheiras estavam distantes entre si por pelo menos $100 \mathrm{~m}$, foi considerado que aleatoriedade e independência foram asseguradas, validando a análise de variância (ANOVA) (LIMA, et al. 2006). Os dados foram analisados pelos programas StatSoft Inc. (1974-2009), STATISTICA 8.0 usando o método de comparação de médias Scott-Knott em 5\% de probabilidade. Para confecção dos gráficos foi usado o programa SIGMAPLOT 11.0 (Systat Sofware Inc.).

\section{Resultados e Discussões}

Para o estoque total de nitrogênio (Figura 1) houve diferença estatística entre os sistemas estudados, sendo que o pasto e o sistema seringueira + açaí foram os que mais estocaram em $100 \mathrm{~cm}$ de profundidade e não diferiram estatisticamente entre si.

Em todas as profundidades estudadas observou-se o mesmo padrão no estoque de $\mathrm{N}$, 
onde a floresta secundária foi o sistema que menos estocou e o pasto e sistema seringueira + açaí os que mais estocaram diferindo entre si apenas na profundidade $10-20 \mathrm{~cm}$, mas com uma diferença pequena entre os sistemas, pasto com 8,38 MG ha-1 e seringueira + açaí 6,61 MG ha ${ }^{-1 .}$

$\mathrm{O}$ estoque de $\mathrm{N}$ encontrado nos sistemas deve-se ao aporte de MO depositado sobre o solo e ao tipo de sistema adotado, conservacionista, onde não há revolvimento da $\mathrm{MO}$, o que favorece a ciclagem de nutrientes e depósito do mesmo ao longo do perfil do solo, haja vista que o N é um elemento de grande mobilidade no solo. (COSTA, et al. 2013).

Figura 1: Estoque de N, em diferentes profundidades, nos solos sob diferentes sistemas, floresta secundaria, pasto e seringueira+açaí. Letras iguais não diferem estatisticamente pelo teste de Scott-Knott a 5\% de probabilidade, as barras verticais apresentam +/- erro padrão. Fonte: Propria. 2018.

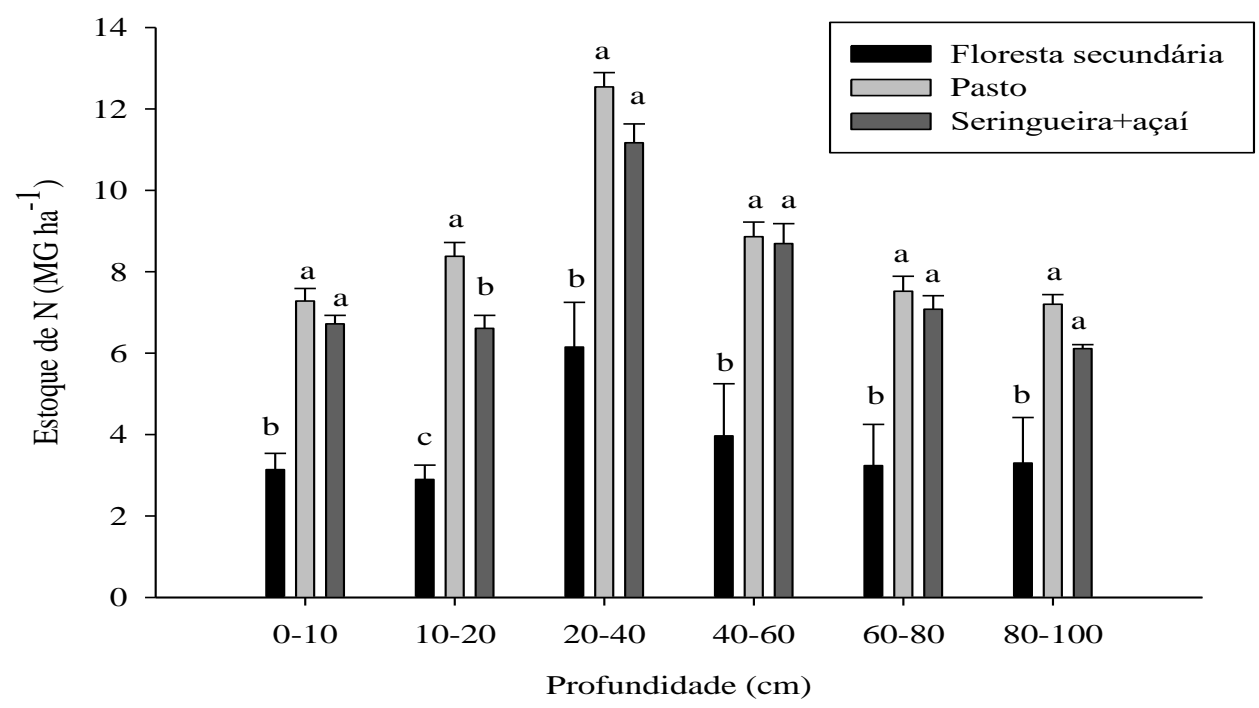

Outro fator importante que contribui ao aporte de MO, principalmente em profundidade são as raízes. As gramíneas, que compõe os pastos, possuem sistema radicular abundante, que contribui efetivamente no aporte de MO no solo (GANZOLLA, et al. 2015). No sistema seringueira + açaí o depósito de matéria orgânica em superfície deve-se ao aporte de MO oriundo da parte aérea das plantas que compõe o sistema, característico dos SAF's, em profundidade, o maior responsável pela deposição de MO são os sistemas radiculares da seringueira e do açaí. A seringueira é uma planta que apresenta sistema radicular profundo e bastante lignificado e o as palmeiras de açaí um sistema mais superficial, mas com grande densidade radicular e raízes também bastante lignificadas. (ABDO, et al. 2012). 


\section{Conclusões}

O pasto foi o que apresentou melhor eficiência no Estoque Total de Nitrogênio.

Os SAF's apresentam grande potencial em aporte de MO o que garante um depósito favorável de nutrientes demostrando as vantagens de se adotar sistemas agroflorestais como alternativa sustentável para agricultura.

\section{Referências}

ABDO, M. T. V. N.; MARTINS, A. L. M.; FINOTO, E. L. (2012) Implantação de sistema agroflorestal com seringueira, urucum e acerola sob diferentes manejos. Pesquisa \& Tecnologia, v. 9, n. 2, 2012.

CAMARGO, F.A.O.; Silva, L.S.; Gianello, C.; Tedesco, J. M. 2008. Nitrogênio orgânico do solo. In: Santos, G. A.; Silva, L. S.; Canellas, L. P.; Camargo, F. A. O. (Ed.) Fundamentos da matéria orgânica do solo: Ecossistemas tropicais e subtropicais. 2. ed., Metrópole, Porto Alegre, Rio Grande do Sul. p. 87-99.

CARVALHO, N. L.; ZABOT. V.; NITROGÊNIO: NUTRIENTE OU POLUENTE?. In: Rev. Elet. em Gestão, Educação e Tecnologia Ambiental v(6), nº 6, p. 960 - 974, 2012.

COSTA, E. M; SILVA, H. F.; RIBEIRO, P.R.A. matéria orgânica do solo e o seu papel na manutenção e produtividade dos sistemas agrícolas; In: ENCICLOPÉDIA BIOSFERA, Centro Científico Conhecer - Goiânia, v.9, n.17; p. 2013

ENGEL, V. L.; PARROTTA, J. A. Definindo a restauração ecológica: tendências e perspectivas mundiais. In: KAGEYAMA, P. Y. et al. (Org.). Restauração ecológica de ecossistemas naturais. Botucatu: FEPAF, 2008. p.1-26.

GANZOLLA, P.R.; GUARESCHI, R.F.; PERIN, A.; PEREIRA, M.G.; ROSSI, C.Q. Frações da matéria orgânica do solo sob pastagem, sistema plantio direto e integração lavourapecuária. In :Semina: Ciências Agrárias, Londrina, v. 36, n. 2, p. 693-704, mar./abr. 2015

GIRACCA, Ecila Maria; NUNES, José Luis. Nitrogênio. Disponivel em: <https://www.agrolink.com.br/fertilizantes/nitrogenio_361444.html> Acesso em: 21 Set. 2018.

LIMA, A.M.N., SILVA, I.R., NEVES, J.C.L., NOVAIS, R.F., BARROS, N.F., MENDONÇA, E.S., SMYTH, T.J., MOREIRA, M.S., LEITE, F.P. (2006a) Soil organic carbon dynamics following afforestation of degraded pastures with eucalyptus in Southeastern Brazil. Forest Ecology Management, 235:219-231. 
PULRONIK, K.; BARROS, N.F. de; SILVA, I.R.; NOVAIS, R.F.; BRANDANI, C.B. Estoques de carbono e nitrogênio em frações lábeis e estáveis da matéria orgânica de solos sob eucalipto, pastagem e cerrado no vale do Jequitinhonha-MG. Revista Brasileira de Ciência do Solo, v.33, p.1125-1136, 2009.

QUEIROZ, J. A. L.; MELÉM JÚNIOR, N. J. Efeito do tamanho do recipiente sobre o desenvolvimento de mudas de açaí (Euterpe oleracea Mart.). Revista Brasileira de Fruticultura, Cruz Das Almas, v. 23, n. 2, p. 460-462, 2001.

SAENGRUKSAWONG, C.; Khamyong, S.; Anongrak, N.; Pinthong, J. (2012) Growths and carbon stocks in rubber plantations on chakkarat soil series, Northeastern Thailand Suranaree Journal Science Technology, v. 19, n. 4, p. 271-278.

SCHROTH, G.; D’ANGELO, S.A.; TEIXEIRA, W.G.; HAAG, D. \& LIEBEREI, R. Conversion of secondary forest into agroforestry and monoculture plantations in Amazônia: Consequences for biomass, litter and soil carbon stocks after 7 years. For. Ecol. Manag., 163:131-150, 2002.

VEIGA, J. B. da; ALVES, C. P.; MARQUES, L.C. T.; VEIGA, D. F. Sistemas silvipastoris naAmazonia Oriental. Belem: EmbrapaAmazonia Oriental, 2000. 62p. (Documentos,56).

VICENTE, L.C. (2006) Origem do carbono orgânico em solos e estoque em agregados sob plantações de seringueira e eucalipto no bioma mata atlântica. Campos Goytacazes: UENF. Dissertação (Produção Vegetal) - 55 Campos dos Goytacazes - RJ, Universidade EStadual do Norte Fluminense - UENF, 60p.

TEIXEIRA, Leopoldo.; GERMANO, Lúcia Vera.; OLIVEIRA, Raimundo F.; JUNIOR, Processos de compostagem usando resíduos das agroindustrias de Açaí e de palmito do Açaizeiro. EMBRAPA (1 Ed.). Circular técnica, Belém 2005 